\title{
GAMPI

\section{Estudo de técnicas e ferramentas para o desenvolvimento de uma animação instrucional para o projeto Rota Segura em Dias de Inundações - RSDI - em Joinville}

Skills and tools study to develop an instructional animation to guide people about Safe Routes in days of flooding in the Joinville city.

STEIN, Tatiane Cristine Pereira; Graduanda; Univille p.tatianecristine@gmail.com

\section{Resumo}

Neste artigo é apresentado um estudo sobre as técnicas e ferramentas utilizadas para o desenvolvimento de uma animação instrucional para orientar a população joinvillense sobre o projeto da Defesa Civil, Rota Segura em Dias de Inundações, RSDI, na cidade de Joinville/SC. Esta animação tem como principal objetivo apresentar o projeto à população de Joinville, instruindo-os sobre como agir e se orientar por meio do sistema de sinalização das RSDI. O resultado da pesquisa destaca a importância do projeto para a cidade de Joinville e as contribuições da animação para reforçar o projeto.

Palavras-chave: Animação Digital, Design Instrucional, Design da Informação.

\begin{abstract}
This article presents a study of the techniques and tools used to develop an instructional animation to guide joinvillense population on the civil defense project, Rota Segura em Dias de Inundações, RSDI, in Joinville / SC. This animation has as main objective to present the project to the population of Joinville, instructing them on how to act and be guided through the RSDI signaling system. The result of research highlights the importance of the project for the city of Joinville and animation contributions to strengthen the project.
\end{abstract}

Keywords: Digital Animation, Instrucional Design, Information Design. 


\section{GAMPI plural 15}

\section{Introdução}

O uso da animação tem se tornado cada vez mais frequente, tanto para fins de entretenimento como educacionais. A grande abrangência que se tem com o uso das animações, permitindo que pessoas de várias classes sociais e níveis de escolaridade tenham acesso ao conteúdo por ela exibido, compreendendo de maneira eficiente e eficaz a mensagem transmitida, faz com que ela se torne uma importante ferramenta para o ensino e a comunicação.

No presente artigo é apresentada uma fundamentação teórica relacionada ao desenvolvimento de uma animação instrucional, que está em desenvolvimento para orientar a população da cidade de Joinville, cidade localizada no norte de Santa Catarina, sobre rotas seguras que podem ser utilizadas em dias de inundações na cidade de Joinville.

O artigo apresenta inicialmente uma problematização que expõe o cenário da cidade de Joinville com relação às fortes chuvas e ocorrências de inundações, o projeto Rota Segura para Dias de Inundações (RSDI), desenvolvido pela Defesa Civil para orientar a população nestas situações, através do desenvolvimento do projeto Rota Segura para Dias de Inundações (RSDI).

São também abordados os temas relacionados à cognição e suas contribuições para o aprendizado, bem como os temas relacionados ao design da informação e design instrucional.

Por fim, são destacadas as considerações finais que demonstram a relevância do projeto como contribuição para a cidade de Joinville.

\section{Problematização}

A cidade de Joinville, situada na região nordeste do estado de Santa Catarina, tem sofrido com o grande crescimento populacional nos últimos anos, acarretando assim em mudanças significativas na infraestrutura da cidade, dos rios, canalizações e aterros. A ocupação da cidade, povoada em uma região de mangue e baía, faz com que inundações e alagamentos tornem-se frequentes, acarretando em perdas econômicas e também colocando a população em situações de risco (ANDRIGHI, 2015).

Com as fortes chuvas, regiões de grande movimentação urbana tornam-se rapidamente inacessíveis. Devido a estes fatores, foi traçada pela Defesa Civil e outros órgão municipais, o projeto Rota Segura para Dias de Inundações (RSDI), com o intuito de auxiliar e orientar a população, a fim de prevenir e reduzir os riscos de incidentes ocasionados pelas inundações (ANDRIGHI, 2015).

O projeto desenvolvido em XXXX foi disponibilizado para a população apenas em forma de mapa, no formato PDF, o que dificulta o acesso e transporte do mesmo, uma vez que se torna necessária a impressão do mapa completo em grande escala, o que dificulta o transporte e a visualização da informação, ou impressão em partes, gerando uma grande quantidade de material. A partir deste problema, foi realizado no Mestrado em Design da Univille um projeto de sistema de informação, propondo a sinalização e elementos visuais para auxiliar na identificação da rota. A proposta, defendida em março de 2015, mas que 


\section{GAMPI plural 15}

ainda não foi implantada, procura facilitar por meio dos elementos visuais desenvolvidos, a orientação dos usuários sem que haja a necessidade de um mapa.

Visando a integração entre graduação e pós-graduação, a partir da proposta apresentada pelo mestrando, identificou-se a oportunidade do desenvolvimento de um TCC do curso de graduação em Design com o intuito de orientar a população sobre a RSDI, tendo como base o Sistema de Informação desenvolvido pelo mestrando. A proposta do TCC é a elaboração de uma animação aplicando a técnica de motion graphics.

A animação produzida terá também o intuito de servir como método educativo nos projetos relacionados à mobilidade urbana ministrados dentro da Univille.

\section{Análise Bibliográfica Sistemática}

Como procedimento para a pesquisa bibliográfica foi aplicada a revisão bibliográfica sistemática, que se caracteriza por uma revisão planejada para a pesquisa e análise de artigos de uma determinada área da ciência, selecionando e avaliando com rigor pesquisas relevantes, para então coletar e analisar dados que possam colaborar com a tomada de decisões (CONFORTO et al, 2011).

Por meio da seleção dos estudos já realizados sobre determinados assuntos, a revisão bibliográfica sistemática permite reunir uma dimensão maior de resultados significativos, impedindo que as conclusões limitem-se apenas à leitura de alguns artigos. Para tanto, é necessário que se tenha definido qual o objetivo da revisão, quais as literaturas disponíveis para então selecionar quais estudos podem ser analisados (SAMPAIO; MANCINI, 2007).

Levy e Ellis (2006) caracterizam a revisão bibliográfica sistemática como sendo parte de um processo, que aplica de uma sequência de passos e atividades, sendo que para se alcançar os resultados desejados, torna-se necessário seguir três fases fundamentais, conforme representado da figura 1 a seguir: 


\section{GAMPI plural 15}

Figura 1: Fases Revisão Bibliográfica Sistemática

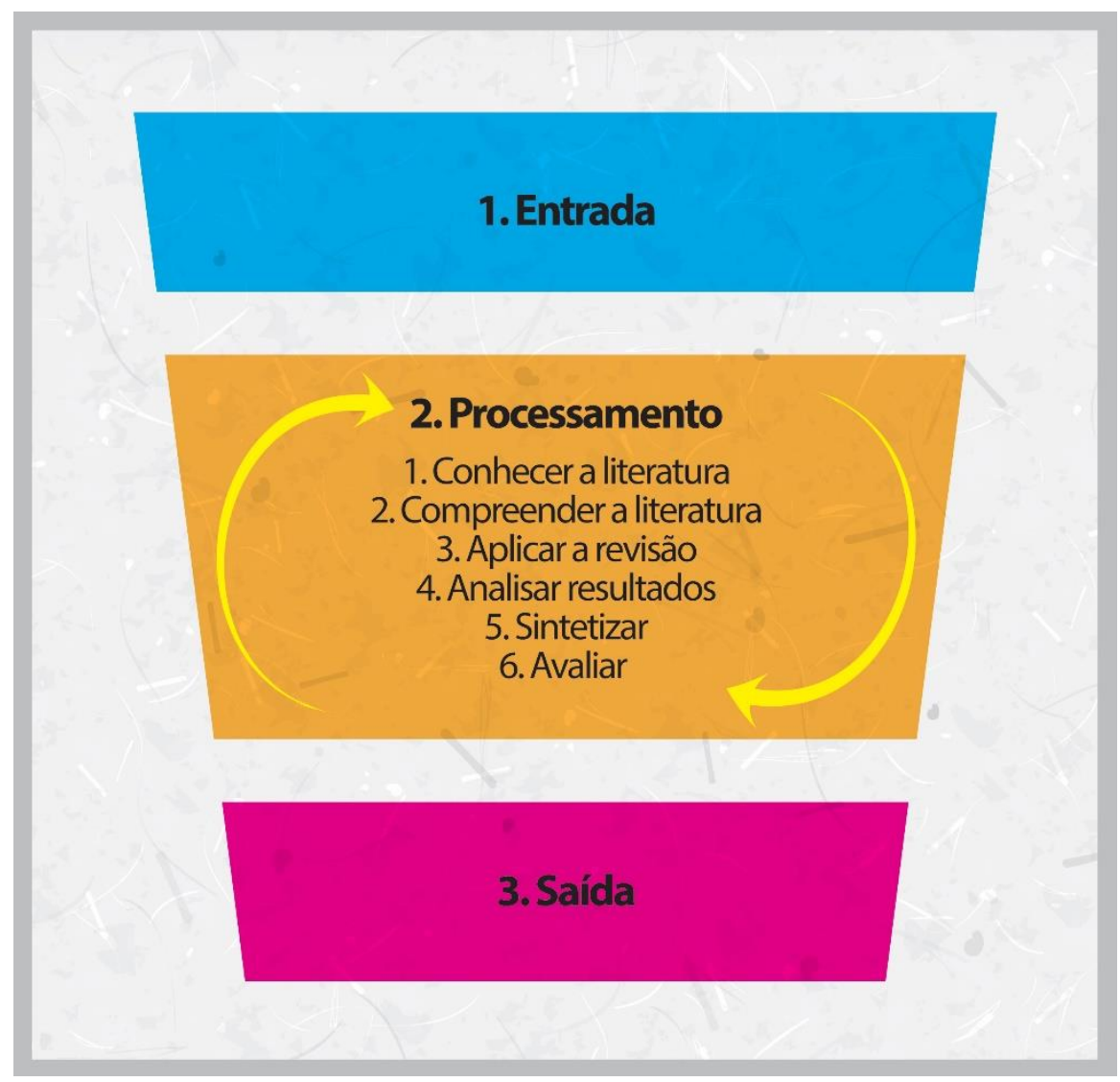

Fonte: Adaptado de LEVY E ELLIS (2006, p. 182)

As informações preliminares que serão analisadas encontram-se na fase de entrada, incluindo também o modo como será conduzida a revisão, descrevendo as técnicas e ferramentas que serão utilizadas na fase de processamento. Na fase de saída, têm-se os relatórios e resumos dos resultados obtidos (LEVY E ELLIS, 2006).

Segundo Rother (2007), no Brasil é recomendado pela Colaboração Cochrane que a revisão bibliográfica sistemática seja realizada a partir de sete passos, conforme apresentado na figura 2 a seguir: 


\section{GAMPI plural 15}

univille

Figura 2: Sete Passos da Revisão Bibliográfica Sistemática

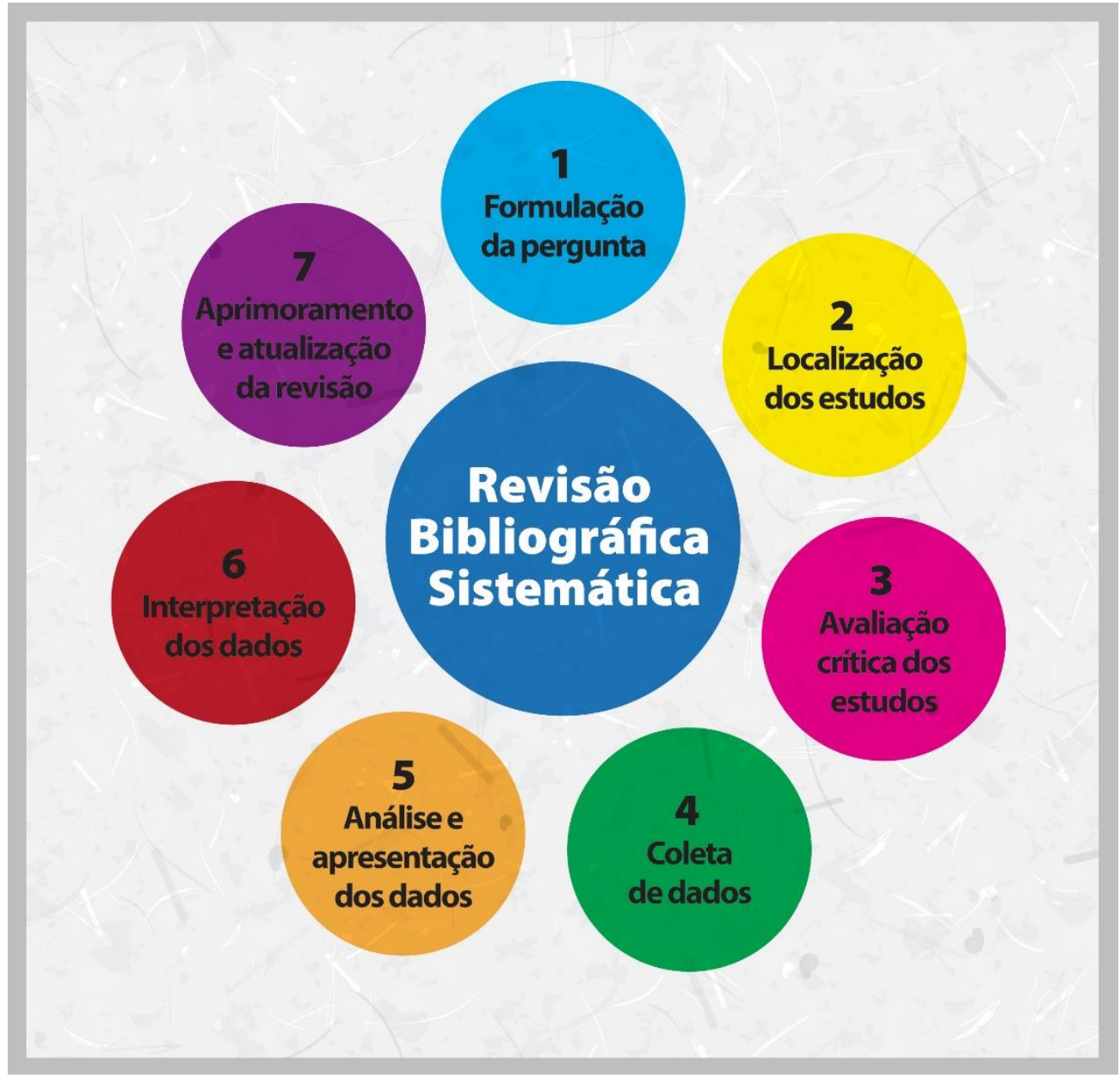

Fonte: Adaptado de ROTHER (2007, p. v)

Para cada fase é realizado um tipo de atividade, conforme apresentado no quadro 1 a seguir:

Quadro 1: Descrição das fases da revisão bibliográfica sistemática

\begin{tabular}{|l|l|}
\hline Passos & Atividade \\
\hline 1. Formulação da pergunta & $\begin{array}{l}\text { Formular uma pergunta sobre o problema, } \\
\text { decidindo assim o que fará parte ou não da } \\
\text { revisão. }\end{array}$ \\
\hline 2. Localização dos estudos & $\begin{array}{l}\text { Buscar por fontes variadas que contenham } \\
\text { estudos relevantes para a pesquisa, detalhando } \\
\text { qual a estratégia de busca utilizada. }\end{array}$ \\
\hline 3. Avaliação crítica dos estudos & $\begin{array}{l}\text { Determinar a validade das fontes selecionadas, } \\
\text { analisando quais fontes farão parte da revisão. }\end{array}$ \\
\hline 4. Coleta de dados & Analisar e resumir os estudos selecionados \\
\hline 5. Análise e apresentação dos dados & $\begin{array}{l}\text { Agrupar os estudos com base na semelhança dos } \\
\text { dados, devendo estes agrupamentos já estarem }\end{array}$ \\
\hline
\end{tabular}




\section{GAMPI plural ${ }^{15}$}

univille

\begin{tabular}{|l|l|}
\hline & $\begin{array}{l}\text { preestabelecidos no projeto, bem como sua forma } \\
\text { de apresentação (gráfica, numérica, etc) }\end{array}$ \\
\hline 6. Interpretação dos dados & $\begin{array}{l}\text { Determinar a validade da fundamentação } \\
\text { encontrada e a aplicação dos resultados, } \\
\text { determinando 0s benefícios e os riscos do } \\
\text { resultado encontrado. }\end{array}$ \\
\hline 7. Aprimoramento e atualização de revisão & $\begin{array}{l}\text { Após publicada, a revisão receberá críticas e } \\
\text { sugestões que deverão ser incorporadas nas } \\
\text { próximas edições, tornando-a uma publicação } \\
\text { dinâmica, que deve estar sempre atualizada } \\
\text { conforme surgirem novos estudos sobre o tema } \\
\text { em questão. }\end{array}$ \\
\hline
\end{tabular}

Fonte: Adaptado de ROTHER (2007, p. v)

De acordo com Sampaio e Mancini (2006, p. 87), “a publicação de estudos de revisão sistemática, bem como de outros que sintetizam resultados de pesquisa, é um passo para a prática baseada em evidência". Quando têm-se a necessidade de trabalhar com um grande volume de informações, buscando compreender a fundamentação teórica-científica de determinado assunto, com a revisão bibliográfica sistemática tem-se maior confiabilidade nos resultados da revisão (CONFORTO et al, 2011).

Para o projeto em questão, a revisão bibliográfica sistemática serviu de suporte para o levantamento de dados sobre a eficácia da aplicação de animações instrucionais para fins instrutivos, bem como das características relevantes que devem estar contidas nelas para sua maior eficiência na transmissão das informações. Para isto, foram realizadas pesquisas sobre estudos realizados em relação ao aprendizado por meio do uso das animações e dos aspectos cognitivos relacionados à este processo.

\section{Cognição}

As informações do mundo físico são detectadas pelos sistemas sensoriais do corpo, por meio da visão, audição, tato, olfato e paladar, e são transmitidas ao cérebro pelo sistema perceptivo. A codificação destas informações é realizada pelo sistema cognitivo, que é responsável pela construção do conhecimento gerado por representações mentais produzidas a partir das experiências vividas pelas pessoas. Estas representações são utilizadas para auxiliar na tomada de decisões, planejamento e atuação das pessoas sobre a realidade vivida. Simbolicamente, os conhecimentos são gerados na mente das pessoas de maneira semelhante aos estímulos a que estão associados, em especial os estímulos visuais e verbais (CYBIS et al, 2010; BARBOSA, 2010).

Ao ser recebida, a informação precisa ser associada aos conhecimentos já adquiridos para então ser aprendida novamente sob sua nova perspectiva. Fatores como experiência, agilidade mental e a habilidade para pensar e gerar novas ideias são decisivos neste processo (KROEMER, 2005). 


\section{GAMPI plural 15}

Além disso, os aspectos relacionados à percepção, memória, raciocínio e controle de atividades mentais também contribuem no processo de compreensão e geração de novas informações pelas pessoas (CYBIS et al, 2010).

\section{Design da Informação}

O design da Informação pode ser definido como "a arte e a ciência de preparação da informação, possibilitando seu uso pelo homem de maneira eficiente e efetiva" (HORN, 1999, p.15). Para a Sociedade Brasileira de Design da Informação,

Design da Informação é uma área do design gráfico que objetiva equacionar os aspectos sintáticos, semânticos e pragmáticos que envolvem os sistemas de informação através da contextualização, planejamento, produção e interface gráfica da informação junto ao seu público-alvo. Seu princípio básico é o de otimizar o processo de aquisição da informação nos sistemas de comunicação analógicos ou digitais (SBDI, 2015, web).

Passos (2008, p. 59) destaca que "o design da informação 'enfoca a tarefa da comunicação na perspectiva de organizar a informação', e está relacionado com a estruturação, a organização e a acessibilidade das informações", tendo como alguns de seus objetivos o desenvolvimento de documentos compreensíveis e o projeto de interações junto aos equipamentos de maneira fácil, natural e agradável (PASSOS, 2008).

Fronza (2014) destaca os estudos de Mayer sobre o assunto, com a definição de que para que ocorra uma aprendizagem significativa em um ambiente multimídia, cinco processos cognitivos devem ser recrutados pelo receptor da mensagem, conforme apresentado na figura 3 abaixo:

Figura 3: Bases do Design Instrucional

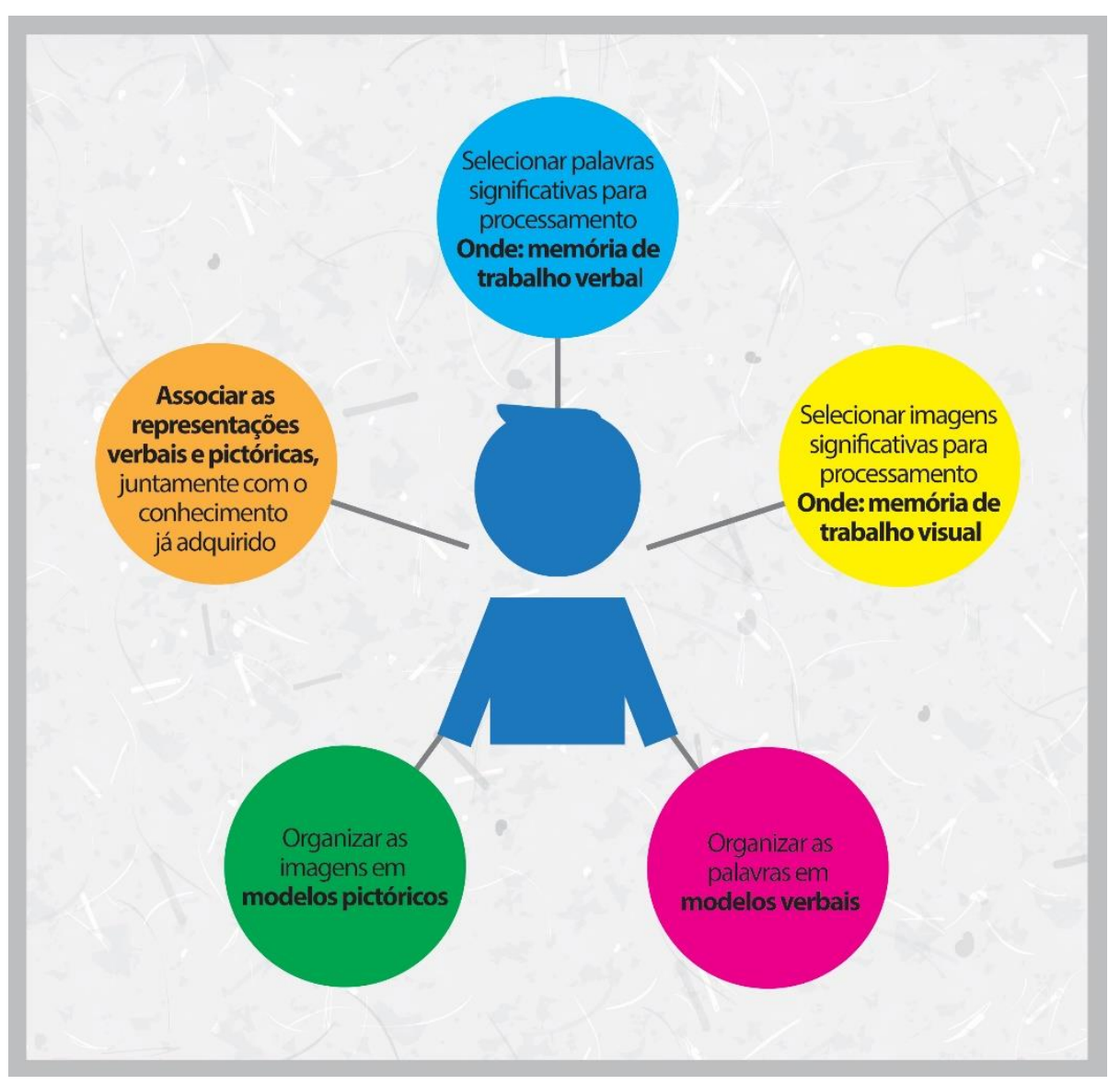




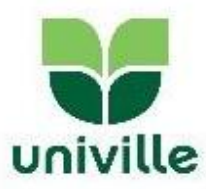

Fonte: Adaptado de FRONZA (2014, p. 54)

Esta organização das informações verbais e não verbais torna-se necessária para que haja a criação de relações estruturais entre os elementos (FRONZA, 2014), uma vez que, em um projeto de hipermídia, é necessário que tanto os sentidos visuais e verbais quanto os sentidos sonoros, tátil e sinestésico estejam concordando com os objetivos e caraterísticas do público alvo do projeto (Portugal, 2010).

Neste aspecto, Coelho Netto (1996) salienta que uma grande quantidade de informações transmitida simultaneamente em vários canais pode fazer com que o usuário fique confuso, tornando assim a mensagem monótona. $\mathrm{O}$ autor destaca que para evitar que esta situação ocorra, é ideal que haja uma certa variação entre os canais, ou seja, quando a informação diminuir no canal visual, o canal sonoro deve ser aumentado e vice-versa, evitando assim que ambos os canais fiquem cheios ou vazios de informações ao mesmo tempo.

Fronza (2014) também destaca que o excesso de informação nas mais variadas mídias faz com que a organização e estruturação destas informações tornem-se aspectos necessários para que a mensagem seja compreensível para os receptores.

A análise da informação pode então começar por meio do agrupamento de informações semelhantes, para então dar início à concepção de seus acessos conforme as características e singularidades do conteúdo e do público ao qual se destina (Passos, 2008).

Neste sentido, a Teoria do Código Duplo, desenvolvida por Pavio, destaca que a informação é processada por dois canais distintos, mas interligados entre si, sendo que um canal é responsável pelo processamento das informações verbais, como o texto e a fala, e outro pelo processamento das informações não verbais, como as imagens e os sons. As informações transmitidas por estes dois canais simultaneamente são assimiladas mais facilmente e, consequentemente, lembradas pelo receptor. Porém, como a capacidade de processamento das informações é limitada, torna-se necessário filtrar o que realmente é relevante para ser transmitido em cada canal, organizando as informações e incorporando-as ao repertório dos receptores (FRONZA, 2014).

\section{Design Instrucional}

O design instrucional pode ser definido como “[...] o planejamento, o desenvolvimento e a utilização sistemática de métodos, técnicas e atividades de ensino para projetos educacionais apoiados por tecnologias" (FILATRO, 2007, p.32).

Para Sartori e Roesler (2005), o design instrucional é a criação e desenvolvimento de projetos, representados por materiais didáticos em ambientes virtuais de ensino e também por tutoriais que servem de apoio aos estudos, otimizando assim o ensino e a aprendizagem de determinadas informações.

O design instrucional parte então de um planejamento, desenvolvimento e aplicação de ensinos didáticos específicos, agregando desde a concepção até sua implementação, artifícios 


\section{GAMPI plural 15}

univille

que beneficiem sua interpretação e flexibilização, facilitando assim sua aprendizagem (FILATRO, 2007).

Filatro destaca que o design Instrucional tem sua origem a partir de três diferentes áreas do conhecimento, conforme apresentado na Figura 4 a seguir:

\section{Figura 4: Bases do Design Instrucional}

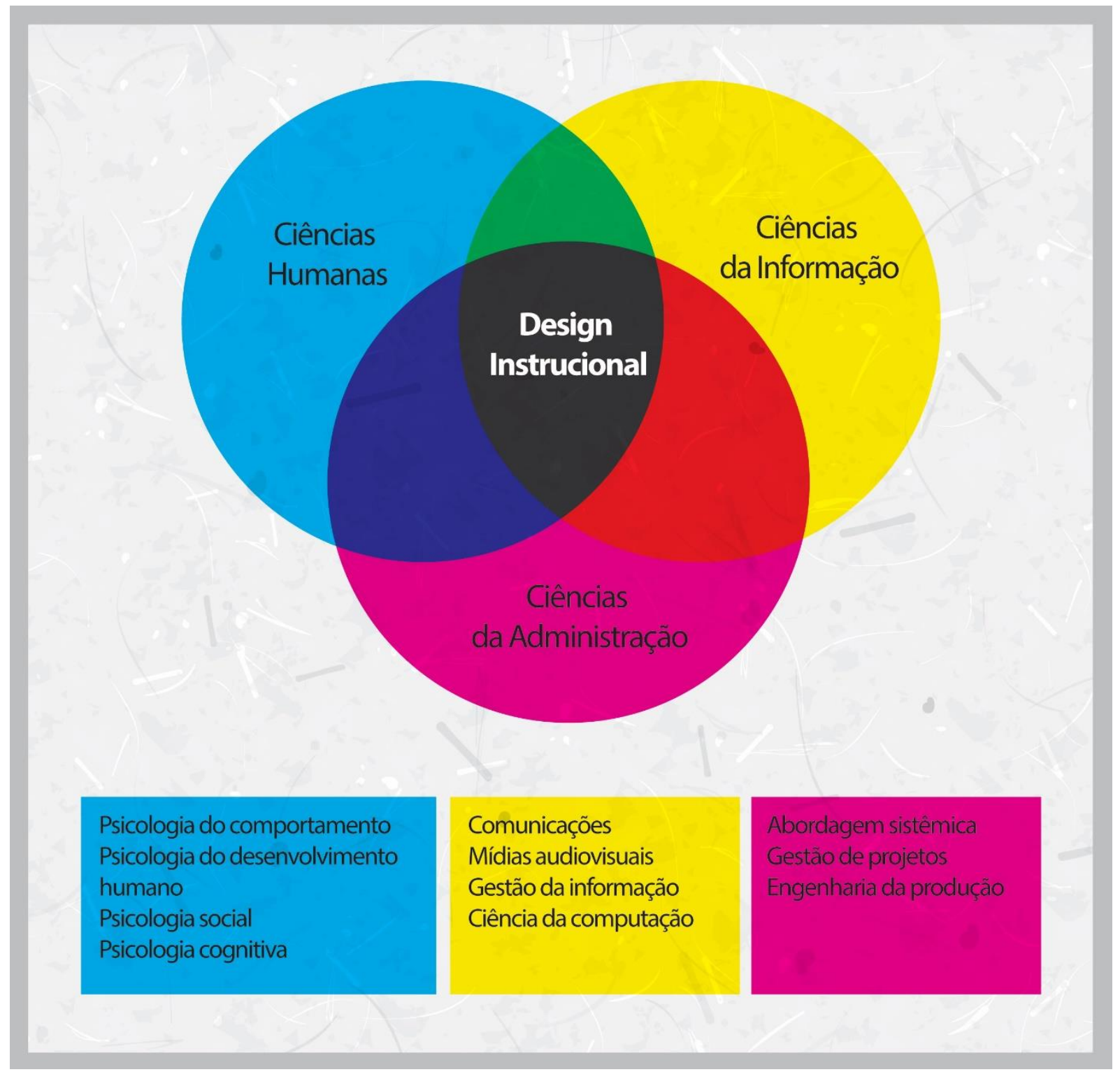

Fonte: Adaptado de Filatro (2008, p.4)

A influência no design instrucional por parte da área das ciências humanas veio a partir da psicologia do comportamento, uma vez que considera a aprendizagem como algo que, além de compreendida, pode ser também controlada pelo uso de instruções. Das ciências da informação o design instrucional obteve sua influência das comunicações, mídias 


\section{GAMPI
plural' ${ }^{15}$}

audiovisuais e gestão da informação, transmitindo a informação por meio de mecanismos tecnológicos. A abordagem sistêmica, gestão de projetos e engenharia da produção foram obtidos por meio das ciências da administração, servindo de apoio para o planejamento educacional (FILATRO, 2008).

A mídia escolhida para a transmissão das informações também influencia no ensino e aprendizagem. Neste ponto, Alves et al (2014) destacam que as animações instrucionais fazem uso de diversos conceitos e elementos disponíveis nas mais diversas áreas do conhecimento, facilitando assim o processo de aprendizagem de determinada tarefa ou instrução, além de servir como fator motivacional para a compreensão do conteúdo a ser transmitido.

De acordo com Spinillo et al (2010) estudos nas áreas de design da informação, psicologia e ergonomia informacional comprovam a importância do uso de instruções visuais animadas como sendo um facilitador do processo de aprendizagem, além de sua eficácia na transmissão das informações de maneira atrativa, fazendo com que o interesse e atenção dos usuários sejam despertados.

$\mathrm{O}$ uso de animações tem se tornado cada vez mais frequente, seja para o entretenimento, através do conto de estórias animadas ou para a propagação de informações, tornando-se bastante popular em diversas áreas do conhecimento, como a psicologia e a educação, para a transmissão de conteúdos educativos e instrucionais (ALVES et al, 2014).

$\mathrm{O}$ design instrucional, por ser um facilitador do processo de aprendizagem, quando incorporado na animação instrucional, tem como finalidade o auxílio para a execução de determinadas tarefas. Sendo assim, é necessário que se trabalhe com objetivos claros, contribuindo para uma melhor compreensão e memorização da informação (GANIER, 2004).

Para Alves et al (2014, p. 74) "a animação instrucional, em particular, incorpora as prerrogativas do design instrucional e, com isso, ela ganha objetivos definidos e responsabilidades perante seus usuários, pois a instrução deve ser transmitida de forma a ser compreendida".

Neste sentido, duas funções podem ser estabelecidas para as animações instrucionais: 1) capacitadora, por reduzir o peso cognitivo da informação, tornando-a mais fácil de ser compreendida e assimilada; 2) facilitadora, pois pela reorganização da informação, facilita a compreensão das informações por apresenta-las de maneira simples e de um modo que se aproxime com a realidade vivida pelo público ao qual se destina (SCHNOTZ e LOWE, 2008).

Alves et al salientam que "ao sair do contexto da educação, a animação (enquanto documento instrucional) atinge um público amplo e variado, necessitando de elementos que funcionem nas mais variadas situações e contextos e para as mais diferentes audiências" (ALVES et al, 2014, p.74).

Nas animações instrucionais, a interação do espectador se dá por meio do seu envolvimento visual, perceptivo e sensorial, tendo como fator motivacional os padrões estéticos e a linguagem gráfica utilizada (ibdem).

Sendo assim, percebe-se a grande contribuição que as animações instrucionais têm para a transmissão das informações de maneira clara e objetiva, podendo atingir os mais variados públicos, contribuindo assim, para uma maior disseminação da mensagem e consequentemente maior instrução da população. Deste modo, no projeto em questão, a animação instrucional contribui para que a informação sobre as rotas de segurança da cidade 


\section{GAMPI
plural ${ }^{15}$}

de Joinville sejam transmitidas para um maior número de pessoas, informando-as e instruindo-as sobre como se orientar em casos de inundações na cidade, contribuindo para a redução de riscos ou desastres proposto pela Defesa Civil local.

\section{Considerações finais}

O uso de instruções animadas tem contribuído muito para a transmissão das informações de maneira clara e objetiva. Os estudos a cerca de como a informação é recebida pelo usuário e de que maneira ele assimila melhor aquilo que lhe é transmitido faz com que a animação desenvolvida se torne mais eficiente e assertiva.

Para a problemática apresentada, os estudos referentes à cognição, design da informação e design instrucional contribuíram para que houvesse um maior entendimento de como ocorre a percepção das informações, permitindo assim que animação a ser desenvolvida atinja seu maior objetivo, que é orientar a população de Joinville sobre o projeto Rota de Segurança para Dias de Inundações - RSDI.

Um maior aprofundamento sobre as técnicas apresentadas ainda se faz necessário, porém o conhecimento adquirido com o que já foi apresentado até o momento permite que, durante o desenvolvimento da animação, estas informações sejam aplicadas para que o resultado final seja ainda mais eficiente e com mais clareza nas informações.

\section{Referências}

ALVES, Marcia Maria; BATTAIOLA, André Luiz; SPINILLO, Carla. Teoria do Fluxo e Animação Instrucional: Contribuições da teoria para o desenvolvimento de instruções visuais animadas. Revista Educação Gráfica. São Paulo, v.18, n. 1, p. 73 - 90, 2014. Disponível em: < http://www.educacaografica.inf.br/revistas/vol-18-numero-01-2014> Acesso em: 08 jun. 2015.

ANDRIGHI, Jean Fabyano. Rota Segura para Dias de Inundações: Desenvolvimento de elementos visuais para auxiliar na locomoção, alertas e localização da população. 2015. 216 f. Dissertação (Programa de Pós-Graduação em Design) - Universidade da Região de Joinville, Santa Catarina.

BARBOSA, Simone Diniz Junqueira; SILVA, Bruno Santana da. Interação humanocomputador. Rio de Janeiro: Elsevier, 2010.

COELHO NETTO, J. T. Semiótica, informação e comunicação: diagrama da teoria do signo. 6ed. São Paulo: Perspectiva, 1996. 


\section{GAMPI}

Conforto, Edivandro Carlos; Amaral, Daniel Capaldo; Silva, Sérgio Luis da. Roteiro para revisão bibliográfica sistemática: aplicação no desenvolvimento de produtos e gerenciamento de projetos. $8^{\circ}$ Congresso Brasileiro de Gestão de desenvolvimento de Produto. Porto Alegre, set. 2011.

CYBIS, Walter et al. Ergonomia e Usabilidade. Conhecimentos, métodos e aplicações. 2ed. São Paulo: Novatec Editora, 2010.

FILATRO, Andrea. Design instrucional na prática. São Paulo: Pearson Education do Brasil, 2008.

Design instrucional contextualizado: educação e tecnologia. $2^{\mathrm{a}}$ ed. São Paulo: Editora Senac São Paulo, 2007.

FRONZA, André Luiz, et al. Recomendações sobre design informacional aplicado em motion graphics. InfoDesign. São Paulo, v. 11, n. 1, p. 50 - 63, mai. 2014.

GANIER, F. Les apports de la psychologie cognitive a la conception d'instructions Procedurales. InfoDesign. São Paulo, v. 1, n. 1, p. 16 - 28, 2004.

HORN, R. Information Design. In JACOBSEN, R. (Ed.), Information Design. Cambridge, MA: MIT Press, 1999.

KROEMER, K. H. E.; GRANDJEAN, E. Manual de Ergonomia: Adaptando o trabalho ao homem. 5 ed. Porto Alegre: Bookman, 2005.

Levy, Y.; Ellis, T.J. A system approach to conduct an effective literature review in support of information systems research. Informing Science Journal, v.9, p.181-212, 2006.

PASSOS, Ravi Figueiredo. O design da informação em interfaces de hipermídias. 2008. 100 f. Dissertação (Programa de Pós-Graduação em Design) - Universidade Anhembi Morumbi, São Paulo.

PORTUGAL, Cristina. Questões complexas do design da informação e de interação. InfoDesign. São Paulo. v. 7, n. 2, p. 1 - 6, nov. 2010.

ROTHER, E. T. Revisão sistemática x Revisão Narrativa. Acta Paulista de Enfermagem. São Paulo, v. 20, n. 2, p. v-vi , jun. 2007.

SAMPAIO, R. F.; MANCINI, M. C. Estudos de Revisão Sistemática: Um guia para síntese criteriosa da evidência científica. Revista Brasileira de Fisioterapia. São Carlos, v. 11, n. 1, p. 83-89, jan./fev. 2007 


\section{GAMPI plural 15}

SARTORI, Ademilde Silveira; ROESLER, Jucimara, Educação superior a distância: gestão da aprendizagem e da produção de materiais didáticos impressos e on-line. Tubarão: Ed. Unisul, 2005. 168 p.

SBDI. Sociedade brasileira de design da informação. Disponível em: <http://www.sbdi.org.br/> Acesso em 16 jun. 2015.

SCHNOTZ, W.; LOWE, R.K. Learning with animation. Research implications for design. New York: Cambridge University Press, 2008.

Spinillo, Carla G.; Souza, José Marconi B. de; Maia, Tiago C; Storck, Guilherme R.; Oselame, Ariely. A Representação Gráfica de Instruções Visuais Animadas: Um estudo analítico na perspectiva da ergonomia informacional. Anais do $10^{\circ}$ Congresso Internacional de Ergonomia e Usabilidade de Interfaces Humano-Computador. Rio de Janeiro: PUC-Rio, maio 2010. 